\title{
Noble-Metal Nanorod Cryoaerogels with Electrocatalytically Active Surface Sites
}

\author{
Dániel Zámbó, Pascal Rusch, Franziska Lübkemann, and Nadja C. Bigall* \\ Cite This: https://doi.org/10.1021/acsami.1c16424 \\ Read Online
}

\section{ACCESS | Lلlll Metrics \& More | 回 Article Recommendations | st Supporting Information}

ABSTRACT: Noble-metal-based electrocatalysts usually contain small nanoparticle building blocks to ensure a high specific surface area as the scene for the surface processes. Here, we show that relatively large noble-metal nanorods are also promising candidates to build up functional macrostructures with prominent electrocatalytic activity. After optimizing and upscaling the syntheses of gold nanorods and gold bipyramid-templated silver nanorods, cryoaerogels are fabricated on a conductive substrate via flash freezing and subsequent freeze drying. The versatile cryoaerogelation technique allows the formation of macrostructures with dendritic, open-pore structure facilitating the increase of the accessible nanorod surfaces. It is demonstrated via electrochemical

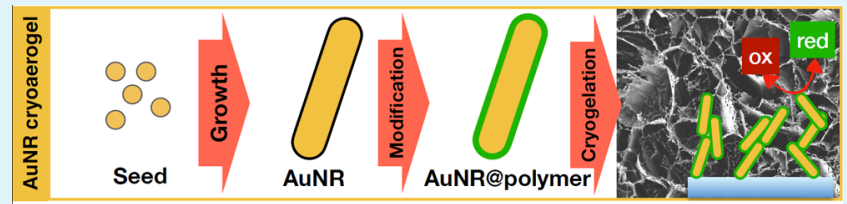
oxidation and stripping test experiments that noble-metal surface sites are electrochemically active in redox reactions. Furthermore, gold nanorod cryoaerogels offer a platform for redox sensing, ethanol oxidation reaction, as well as glucose sensing. Compared to their simply drop-cast and dried counterparts, the noble-metal nanorod cryoaerogels offer enhanced activity due to the open porosity of the fabricated nanostructure while maintaining structural stability.

KEYWORDS: cryoaerogel coatings, gold nanorods, silver nanorods, assembly, electrocatalysis

\section{INTRODUCTION}

Noble-metal nanoparticles have been in the spotlight of the research due to their outstanding properties being exploited in optical, biomedical, catalytic, and sensing applications. ${ }^{1-8}$ While the well-designed nanoparticle properties enabled the possibility of their use in advanced applications, these often cannot be exploited at the macroscale. Hence, besides tailoring the nanoparticle building blocks themselves, ${ }^{9}$ techniques for producing functional assemblies from them have attracted excessive research interest in the recent decade. ${ }^{10-14}$ In electrocatalysis, the demand for the fabrication of macroscopically manageable but nanostructured materials is of central importance. Modern assembly approaches, such as evaporation-induced self-assembly ${ }^{11,15,16}$ and nanocrystal gelation, ${ }^{17-20}$ offer novel routes toward the preparation of active electrode materials with stable structural and electrochemical properties.

Aerogelation is one of these new techniques enabling the assembly of the tailored noble-metal building blocks into functional macrostructures. ${ }^{17,20-26}$ It can be carried out via the chemical $^{19,27}$ or physical ${ }^{28-30}$ destabilization of the nanocrystal solutions to trigger the formation of the interconnected gel structure. Recently, chemical destabilization and ligand desorption led to the assembly of a large variety of nanoscopic building blocks into mono- and multimetallic aerogels with catalytic activity. ${ }^{31}$
It is important to note that preserving the initial porosity of chemically gelated structures is challenging and requires the use of additional fabrication steps (milling, grinding) and additives (e.g., Nafion), ${ }^{27,32-35}$ from which the destruction of the original nanostructure can be inferred. Here, the cryoaerogelation provides an alternative route toward porous, stable, and versatile nanocrystal aerogel coatings on various substrates. ${ }^{17}$

Additionally, we have also demonstrated recently that cryoaerogelation is a promising route to fabricate gel coatings for electrochemical applications. ${ }^{36-40}$ Cryoaerogelation is a novel approach practically including two main steps: (i) the flash freezing of the highly concentrated and colloidally stable aqueous nanoparticle solution and (ii) the subsequent freeze drying of the evolved structure. In the freezing step, the formation of the ice crystals (under the control of their growth via the freezing medium) confines the nanoparticles (NPs) into the crystal boundaries forming sheetlike structures. ${ }^{37,38}$

Received: August 27, 2021

Accepted: October 21, 2021 
Scheme 1. Schematic Flowchart of the Cryoaerogel Preparation ${ }^{a}$

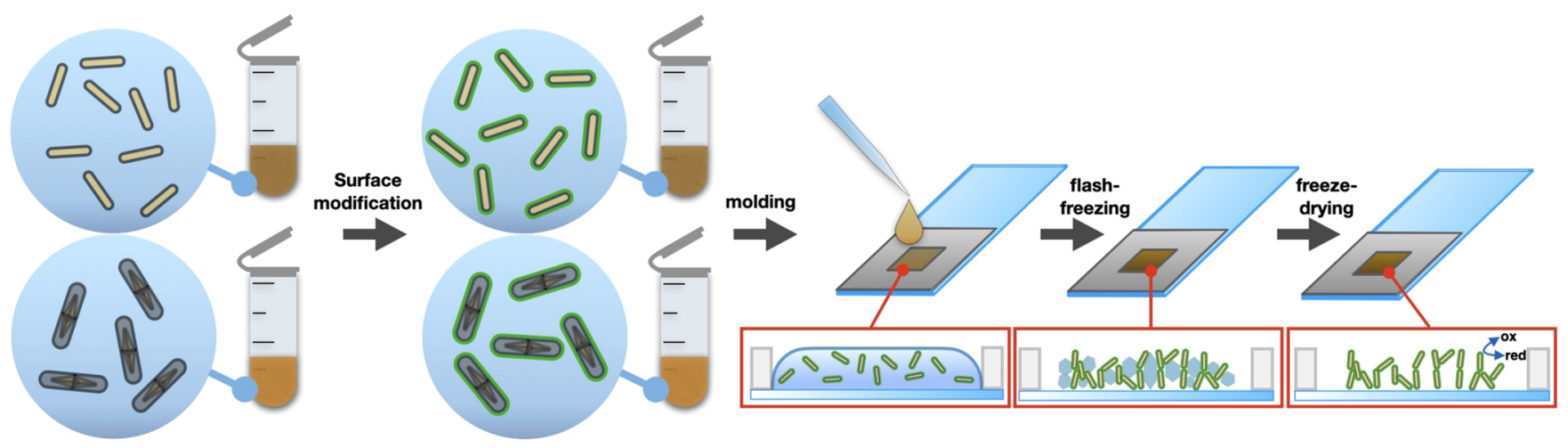

${ }^{a}$ Gold and silver NRs are synthesized in an aqueous medium, surface-modified using a conductive polymer (PEDOT:PSS), and deposited into the mold preformed on the surface of MPTMS-coated ITO. The formation of the gel structures is triggered via flash freezing the NR solutions in cooled isopentane. In the last step, lyophilization is used to remove the ice crystal template. The obtained aerogel-coated ITO glasses are employed as working electrodes to study the electrochemical properties.

The ice template is then removed using lyophilization to preserve the structure prepared in the frozen state.

Noble-metal nanoparticles for (electro)catalytic purposes are generally small (sub-10 $\mathrm{nm}$ in diameter), ${ }^{20,37,39}$ which ensures the high surface-to-volume ratio. Using these small sizes is, however, also a practical consequence of their synthesis methods offering high nanoparticle concentrations and low polydispersity with a relatively low technical demand. Therefore, metal nanoparticle gel structures mainly consist of small, spherical particles. The use of cryoaerogels as electrocatalysts with multimodal porosity is still in its infancy: first, we have demonstrated recently the enhanced electrocatalytic activity of cryoaerogels and cryohydrogels consisting of small $\mathrm{Au}, \mathrm{Pd}$, and Pt nanoparticles over their dried nanoparticle films. ${ }^{37}$ As another alternative, nanoporous gold and silver have also been developed and their advantageous electrocatalytic properties in ethanol oxidation reaction (EOR) and glucose sensing were proven. ${ }^{41-44}$ Nanorods (NRs) are underrepresented in these studies, due to their larger size, more complex preparation route, and most importantly the scarcity of synthesis routes providing high enough nanorod concentrations. However, since the pioneering works of Murphy ${ }^{45,46}$ and El-Sayed, ${ }^{47}$ novel routes have been discovered to prepare highly monodisperse, tailorable gold and silver nanorods using additives to break the symmetry. ${ }^{48,49}$ While gold nanorods can be synthesized in the well-known seeded growth method, this is not applicable for silver nanorods. However, the growth of a silver shell around monodisperse gold bipyramids revolutionized the preparation of monodisperse silver NRs. ${ }^{49}$ Via further optimizing and combining the methods available in the literature, we demonstrate in this work that AuNRs and AgNRs can be synthesized in high amounts and concentrations suitable for cryoaerogelation. The chemical stability of AgNRs is a common issue (i.e., these particles tend to oxidize), ${ }^{50}$ which we targeted to overcome with a surface modification step. Although these NRs have relatively large dimensions, their potential in the form of cryoaerogel coatings in an electrocatalytic application is demonstrated, and the redox reactions and electrochemical stripping processes on their active sites are revealed.

In this work, a novel method for assembling gold and silver NRs into porous, solid-supported cryoaerogel structures and their electrochemical properties are presented. After the upscaled wet-chemical synthesis of the NRs, their surfaces are grafted by a conductive polymer (poly(3,4-ethylenedioxythiophene) poly(styrenesulfonate), PEDOT:PSS) to enhance their stability and to replace the nonconductive original ligands. The cryoaerogel coatings are prepared via flash freezing (in cooled isopentane at $113 \mathrm{~K}$ ) and subsequent freeze drying (under $0.06 \mathrm{mbar}$ ) of the concentrated NR solutions deposited onto 3-(mercaptopropyl)trimethoxysilane (MPTMS)-coated indium tin oxide (ITO) glasses. ${ }^{37,38}$ The steps of the electrode fabrication are schematically depicted in Scheme 1. It is demonstrated that the cryoaerogel coatings have a stable, dendritic, open-pore structure ensuring the high contact area between the nanorods and the electrolyte pointing out their superior properties compared to the drop-cast and ambient dried NR films. Importantly, the polymer grafting does not hinder the electrochemical stripping and the electrooxidation of the noble-metal nanorods; the surface of the building blocks is electrochemically available for electrocatalytic reactions. This is further proven by test experiments, where the potential of Au nanorod cryoaerogel coatings in redox sensing, ethanol oxidation reaction (EOR), and glucose redox reaction is presented. The cryoaerogel coatings drastically increase the conductivity of the MPTMS-coated ITO substrate, which is demonstrated using electrochemical impedance spectroscopy (EIS). These results demonstrate that cryoaerogels from relatively large gold and silver nanorods are of great interest in electrocatalytic reactions, which offers a novel electrode preparation route using a rich variety of multimetallic building blocks based on nanorod templates.

\section{RESULTS AND DISCUSSION}

\subsection{Synthesis and Characterization of the Building}

Blocks. Two types of noble-metal nanorods were chosen as model systems: gold and silver NRs. Gold NRs were synthesized following the novel protocol of González-Rubio et al. ${ }^{48}$ based on the disconnection of symmetry breaking from the seeded growth. The synthesis includes the preparation of 1-2 $\mathrm{nm} \mathrm{Au}$ seeds followed by the growth of NRs in the presence of CTAB and $n$-decanol. While the original protocol has three steps, we have tuned and modified the first two steps to prepare AuNRs with narrow size distribution (the average length and width of the obtained NRs are 46 and $11 \mathrm{~nm}$, 

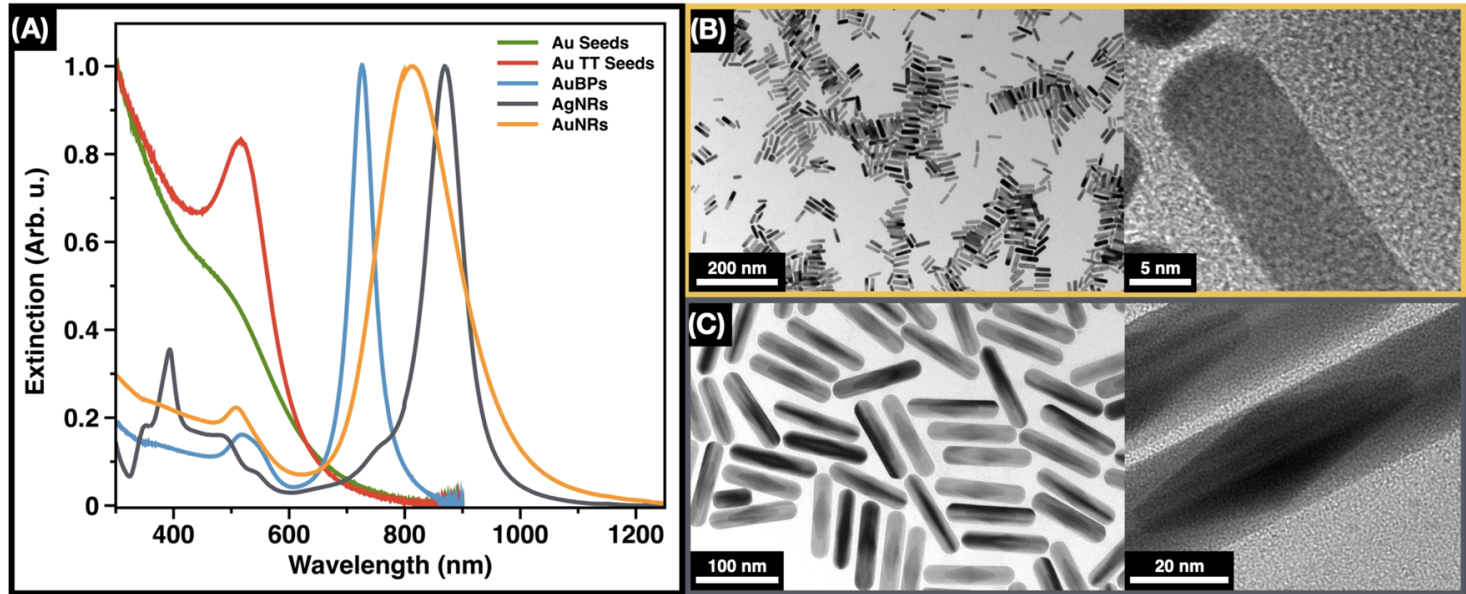

Figure 1. Extinction spectra of the final nanorod building blocks and the intermediate products (single-crystalline Au seeds, thermally treated Au seeds, Au bipyramids) used in the growth of the nanorods (A). Transmission electron spectroscopy (TEM) and high-resolution transmission electron microscopy (HRTEM) images of the as-synthesized AuNRs (B) and AgNRs (C). The HRTEM image in (C) shows the Au bipyramid embedded into the AgNR.

respectively; see the SI for experimental details) and a high concentration.

Silver NRs were prepared following a multistep growth method partially adapted from the work of $\mathrm{Li}$ et al. ${ }^{31}$ and Sánchez-Iglesias et al. ${ }^{49}$ The four-step synthesis route includes the preparation of small, single-crystalline Au seeds, a thermal treatment to induce their pentatwinning followed by the growth of Au bipyramids (BPs), and finally the overgrowth of the BPs into rod-shaped AgNRs (extinction spectra of the intermediate particles and the fine tuning of the AuBP sizes can be seen in Figures S1 and S2). Gold bipyramids were synthesized in uniform shape and narrow size distribution (Figure S3) to ensure the preparation of high-quality AgNRs. Upon upscaling the growth protocol, AgNRs in high yield and with high shape purity were obtained in high concentrations. The formation of silver nanorods is accompanied by a prominent color change from brown to green and finally to orange within $1 \mathrm{~h}$ (Figure S4), resulting in nanorods with an average length of $108 \mathrm{~nm}$ and an average width of $25 \mathrm{~nm}$.

Figure $1 \mathrm{~A}$ shows the extinction spectra of the final NRs as well as the intermediate NPs (seeds, pentatwinned seeds, and bipyramids). Both AuNRs and AgNRs possess a strong localized surface plasmon resonance (LSPR) peak centered at 810 and $869 \mathrm{~nm}$, respectively. While the AuNRs consist of pure gold (Figure 1B), the AgNRs have a core-shell structure: the AuBPs are clearly visible inside each silver nanorod in Figure $1 \mathrm{C}$.

Due to the fact that the nanorods are stabilized by CTAB $/ n$ decanol (for AuNRs) and CTAC (for AgNRs), two main challenges have to be overcome. On the one hand, long aliphatic chains of $\mathrm{CTA}^{+}$significantly lower the overall conductivity upon the formation of an assembled structure, especially with a targeted application in electrocatalysis. On the other hand, silver nanoparticles have low shape stability due to the high mobility of the $\mathrm{Ag}^{+}$ions and their sensitivity toward oxidation. Thus, the surface modification of the nanorods is of high importance to increase both the stability of the building blocks and the overall conductivity of the cryoaerogel structures assembled in a later step. A conductive polymer (PEDOT:PSS) was chosen as a new ligand to replace the original $\mathrm{CTAB} / \mathrm{CTAC}$ bilayer following the protocol published by the Kraus group. ${ }^{52,53}$ Figure 2 shows that the morphology of the nanorods remained intact upon the polymer grafting; however, a significant charge inversion from positive to negative took place, indicating a successful ligand exchange for both types of nanorods (Figure 2C). Extinction spectra display solely slight changes upon surface modification, which also proves the retained morphology and the unchanged optical properties after the polymer grafting (Figure S5). It is important to note that the PEDOT:PSS shell protects the silver nanorods from dissolution and oxidation under ambient conditions, while the silver shell almost completely vanishes in time in the case of the CTAC bilayer (Figure S6).

2.2. Structural Properties of the Cryoaerogels. The PEDOT:PSS-modified noble-metal nanorods were used as building blocks for the fabrication of cryoaerogel electrodes. To enhance the attachment of the nanorods to the ITO surface as well as to increase the stability of the cryoaerogel coatings, functionalization of the ITO surface with 3-(mercaptopropyl)trimethoxysilane (MPTMS) was performed. The functionalization procedure was optimized in terms of the coverage and compactness of the MPTMS monolayer using the electrochemical redox reaction of $1 \mathrm{mM} \mathrm{K}_{4}\left[\mathrm{Fe}(\mathrm{CN})_{6}\right]$ as a model system (Figure $\mathrm{S} 7$ shows the $\mathrm{CV}$ curves and the peak separations of the MPTMS-coated ITO electrodes for different MPTMS concentrations and reaction times). The most complete coverage was achieved using 2 (V/V)\% MPTMS in toluene for $2 \mathrm{~h}$ at $70^{\circ} \mathrm{C}$ and room temperature for $24 \mathrm{~h}$. After the purification and concentration of the PEDOT:PSS-coated NRs, the solutions were deposited into a preformed mold on the MPTMS-coated ITO glass slides. By dipping the slides into the freezing medium (isopentane, cooled to $113 \mathrm{~K}$ with liquid nitrogen), the swiftly frozen water forms ice crystals confining the nanorods into the boundaries of the growing crystals. After an aging period of $24 \mathrm{~h}$ in liquid nitrogen, the cryogel coatings were freeze-dried at $0.06 \mathrm{mbar}$ to remove the ice template resulting in dendritic, sheetlike structures with open porosity as Figure 3 shows (for the detailed description of the electrode preparation, see the SI; Figure S8 depicts the electrodes before and after the cryoaerogelation). The sheets have an average thickness of $c a .200 \mathrm{~nm}$ and consist of nanorods, which retain their original morphology upon freezing and drying most likely due to the steric repulsion provided by the ligands. The 


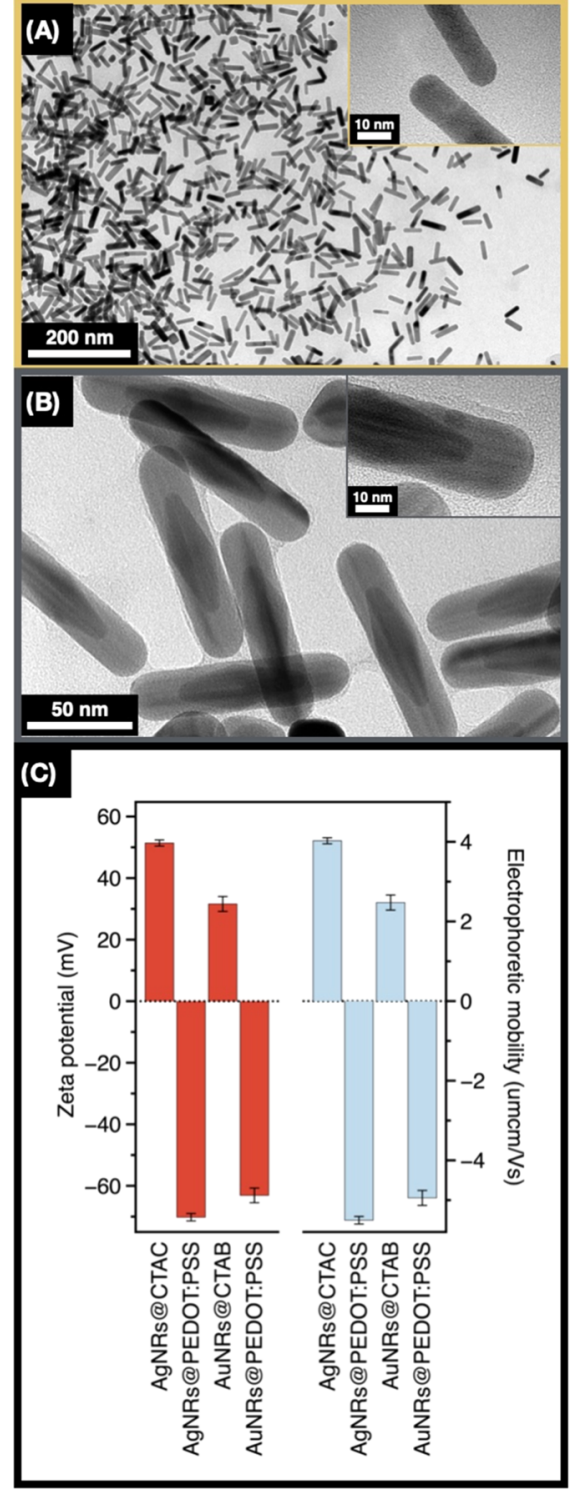

Figure 2. Morphology and charge of the NRs after polymer grafting. TEM and HRTEM images of AuNRs (A) and AgNRs (B) showing no change in the nanoparticle morphology upon modifying them with PEDOT:PSS. $\zeta$-Potentials and electrophoretic mobilities (C) clearly indicating the inversion of the NRs' charge from highly positive to highly negative upon polymer grafting.

procedure ensures the formation of homogeneous nanorod cryoaerogel coatings on the surface of the electrode. The extinction spectra of the cryoaerogelated nanorods roughly resemble their original spectra in solution; however, a prominent redshift as well as broadening of their LSPR peak can be observed (Figure S9). This can be attributed to the nanorod-nanorod interactions as a consequence of their confinement in the formed sheets.

In contrast, homogeneous nanorod films could not be prepared via simple drop casting and ambient drying of the nanoparticle solutions. Using the same NR concentrations as for the cryoaerogel coatings, ambient drying resulted in nanorod films suffering from the coffee stain effect with mostly monolayer or submonolayer thicknesses at the center as well as uncontrollable accumulation at the edge of the mold (Figure S9), which is the electrochemically active area during the measurement. This emphasizes the advantages of the cryoaerogel-coated electrode preparation, which provides homogeneous, highly porous nanorod aerogel structures on the entire electrode surface, that cannot be achieved using conventional drying techniques.

2.3. Electrochemical Behavior of the CryoaerogelCoated Electrodes. Upon assembling the noble-metal nanorods into gel structures, the question arises, whether the employed polymer layer blocks the surface of the rods and hinders redox reactions driven by the nanorod surfaces. Therefore, the obtained nanorod cryoaerogel-coated electrodes were tested in electrochemical model reactions to reveal the accessibility of the nanorod surfaces during electrocatalysis. First, the electrochemical stripping of the noble metals was tested in multiple $\mathrm{CV}$ cycles using $20 \mathrm{mM} \mathrm{KCl}$ as a supporting electrolyte. Second, oxidative treatment was carried out in 0.3 $\mathrm{M} \mathrm{KOH}$ electrolyte. To test the performance of the electrodes in redox sensing and EOR, further electrochemical model experiments were performed. To shed light on the overall resistance and capacitance of the cryoaerogel-coated electrodes, electrochemical impedance spectroscopy was employed. For all of the electrochemical measurements, simply drop-cast and dried (under ambient conditions) NR films were used as reference systems to reveal the advantages of using cryoaerogel structures over simply dried NR films.

2.3.1. Electrochemical Stripping via $\mathrm{Cl}^{-}$lons. The cryoaerogel-coated electrodes were gently rehydrated inside the three-electrode electrochemical cell by the supporting electrolytes. Multiple cyclic voltammetric scans were performed between -0.6 and $+1.0 \mathrm{~V}$ bias potentials (vs $\mathrm{Ag} / \mathrm{AgCl}$ in $3 \mathrm{M} \mathrm{NaCl}$ reference electrode) using the nanorod cryoaerogel-coated ITO as a working electrode. Figure 4A,C shows the evolution of the voltammograms in $20 \mathrm{mM} \mathrm{KCl}$ from the 1 st to the 15th scans for AuNR- and AgNRcryoaerogel-coated electrodes, respectively. AuNRs display three main characteristic redox reactions (Figure 4A): two during the anodic (I, II) and one (III) during the cathodic scan. While the first anodic peak has an onset potential of $+0.18 \mathrm{~V}$ (centered at $+0.38 \mathrm{~V}$ ), the second peak does not evolve entirely and has an onset of $c a .+0.5 \mathrm{~V}$. These two peaks (I and II) can be attributed to the two-step oxidation of the $\mathrm{Cl}^{-}$anions on the surface of the gold nanorods forming first $\mathrm{Cl}_{3}{ }^{-}$and later $\mathrm{Cl}_{2} \cdot{ }^{54}$ Nevertheless, highly positive bias potentials might also induce the formation of $\left[\mathrm{AuCl}_{4}\right]^{-}$ complexes, which can be reduced to $\left[\mathrm{AuCl}_{2}\right]^{-}$during the cathodic scan (manifesting in peak III centered at $-0.2 \mathrm{~V}$ ).

The cryoaerogel coating of AgNRs displays the formation of silver chloride species and their subsequent reduction back to silver (Figure 4C), demonstrating a successful stripping of the silver and therefore the electrochemical availability of the NR surfaces. Peaks I and II (at $+0.2 \mathrm{~V}$ and around $+0.5 \mathrm{~V}$ ) indicate the formation of $\mathrm{AgCl}$ and $\mathrm{AgCl}_{2}{ }^{-}$due to the presence of the $\mathrm{Cl}^{-}$. ${ }^{55}$ These species can be reduced to $\mathrm{Ag}^{0}$ during the cathodic scan. Peak III can be attributed to the reduction of $\mathrm{AgCl}$ to $\mathrm{Ag}$, while peak IV-being more prominent with an increasing number of cycles-indicates the reduction of $\mathrm{AgCl}_{2}{ }^{-}$complex back to $\mathrm{Ag}^{0.56}$.

The prominent electrochemical responses in the presence of $\mathrm{Cl}^{-}$for both systems imply that the surface of the noble-metal nanorods are electrochemically active and available: specific surface-driven redox processes can be observed in electrochemical stripping reactions. 

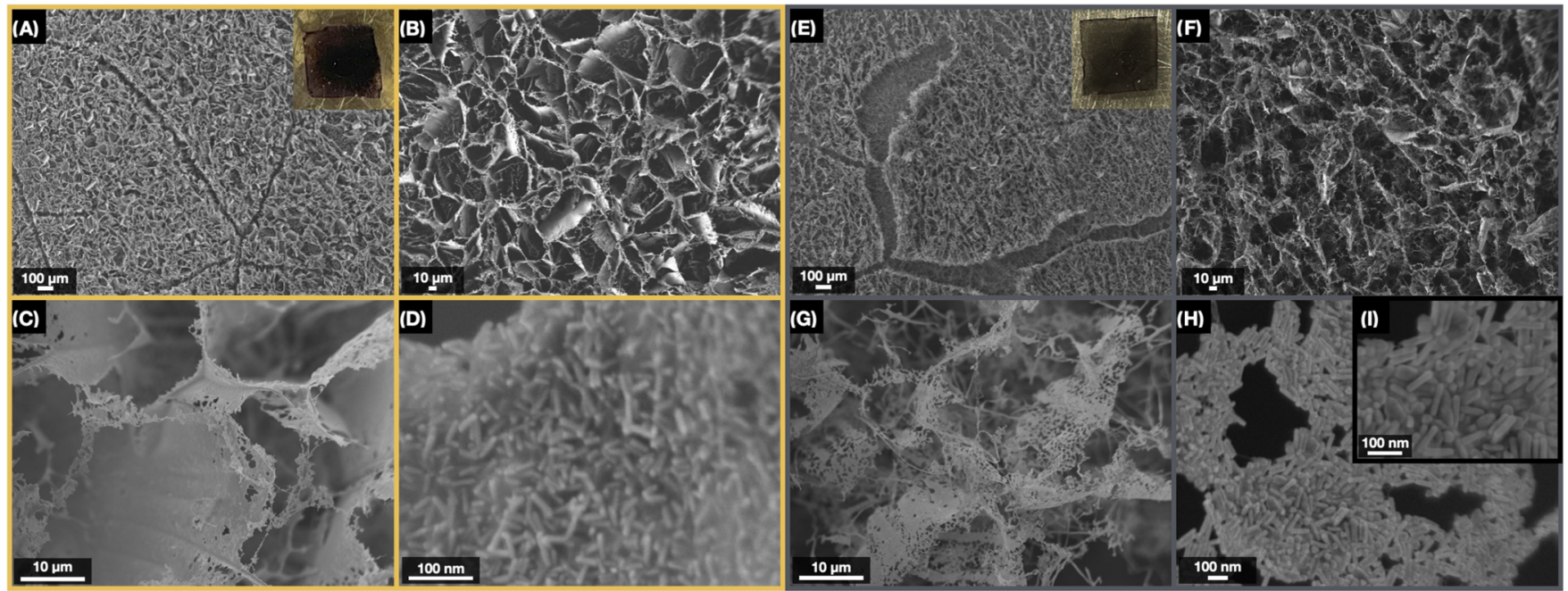

Figure 3. Scanning electron microscopy (SEM) images showing the micro- and nanostructure of the cryoaerogel coatings prepared from AuNRs $(\mathrm{A}-\mathrm{D})$ and AgNRs (E-I). The insets in (A) and (E) show the physical appearance of the cryogel-coated electrode surfaces with a dimension of 0.5 $\times 0.5 \mathrm{~cm}$.
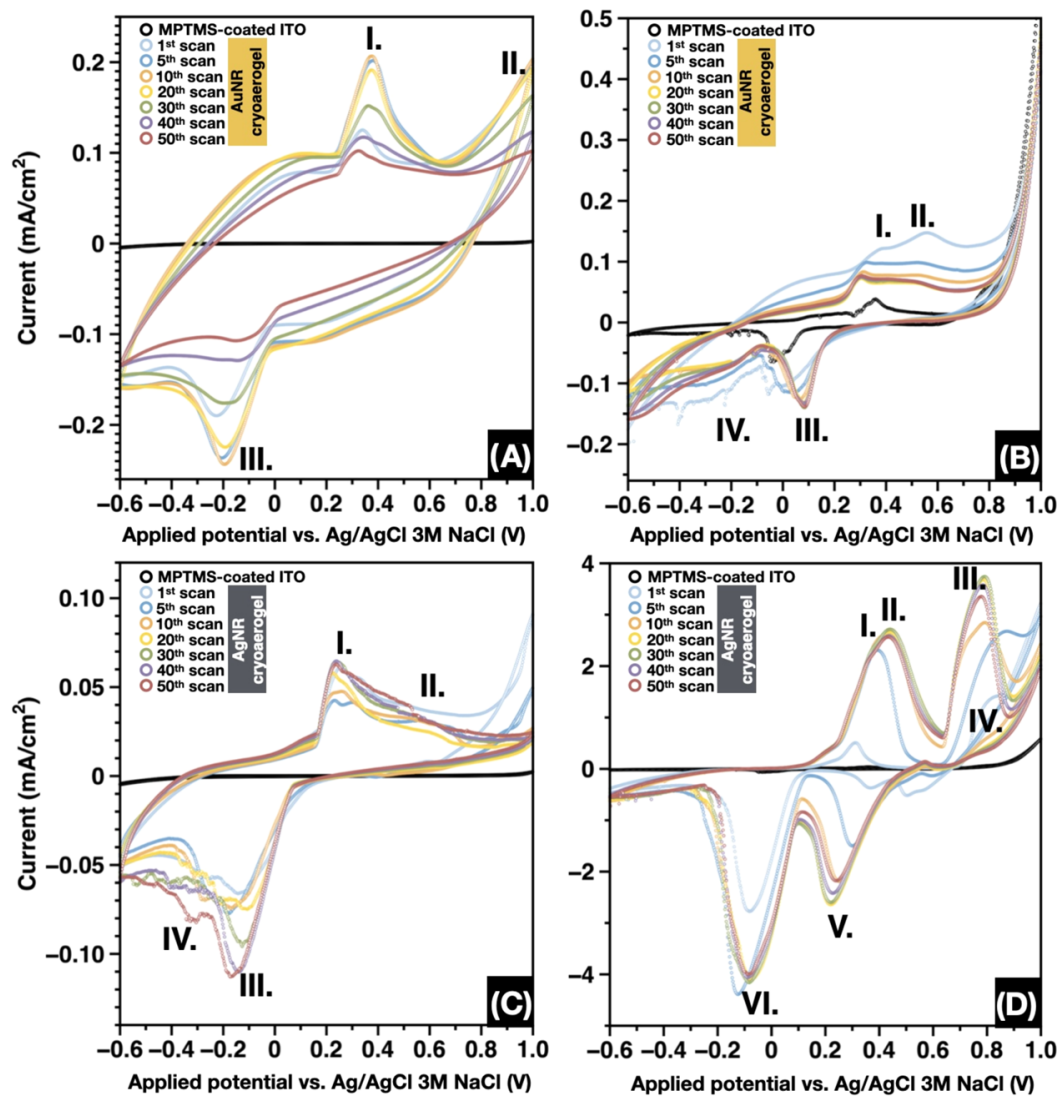

Figure 4. Cyclic voltammograms of AuNR-based (A, B) and AgNR-based (C, D) cryoaerogel-coated electrodes in $20 \mathrm{mM} \mathrm{KCl} \mathrm{(A,} \mathrm{C)} \mathrm{and} 0.3 \mathrm{M}$ $\mathrm{KOH}(\mathrm{B}, \mathrm{D})$ electrolytes. Roman numbers mark the bias potential regions of the characteristic redox processes described in the main text.

\subsubsection{Electrochemical Reactions in the Presence of $\mathrm{OH}^{-}$.} Although electrochemical stripping showed the availability of the nanorod surfaces, numerous electrocatalytic and sensing applications require alkaline $\mathrm{pH}$, which is mostly achieved by means of $\mathrm{KOH}$ as a supporting electrolyte. Therefore, we tested the electrochemical response of the prepared cryoaerogel electrodes during oxidative treatment in the presence of $\mathrm{OH}^{-}$anions. Figure 4B shows the $\mathrm{CV}$ curves of the AuNR cryoaerogel-coated electrode in $0.3 \mathrm{M} \mathrm{KOH}$ electrolyte in the same bias potential range as used for the $\mathrm{Cl}^{-}$treatment. In the anodic scans, peaks I and II show the formation of $\mathrm{Au}_{2} \mathrm{O}_{3}$ as the main product upon oxidizing $\mathrm{Au}^{0}$. While peak I can be attributed to the buildup of the first oxide layer, ${ }^{57}$ peak II at higher bias potentials most probably imply the formation of the multilayered oxide. The formed oxide layer is first reduced to $\mathrm{Au}^{0}$ during the cathodic scans (peak III at $+0.1 \mathrm{~V}$ ) followed by the desorption of the hydroxide anions at higher negative biases (broad shoulder marked as peak IV). ${ }^{57}$ Silver nanorods 


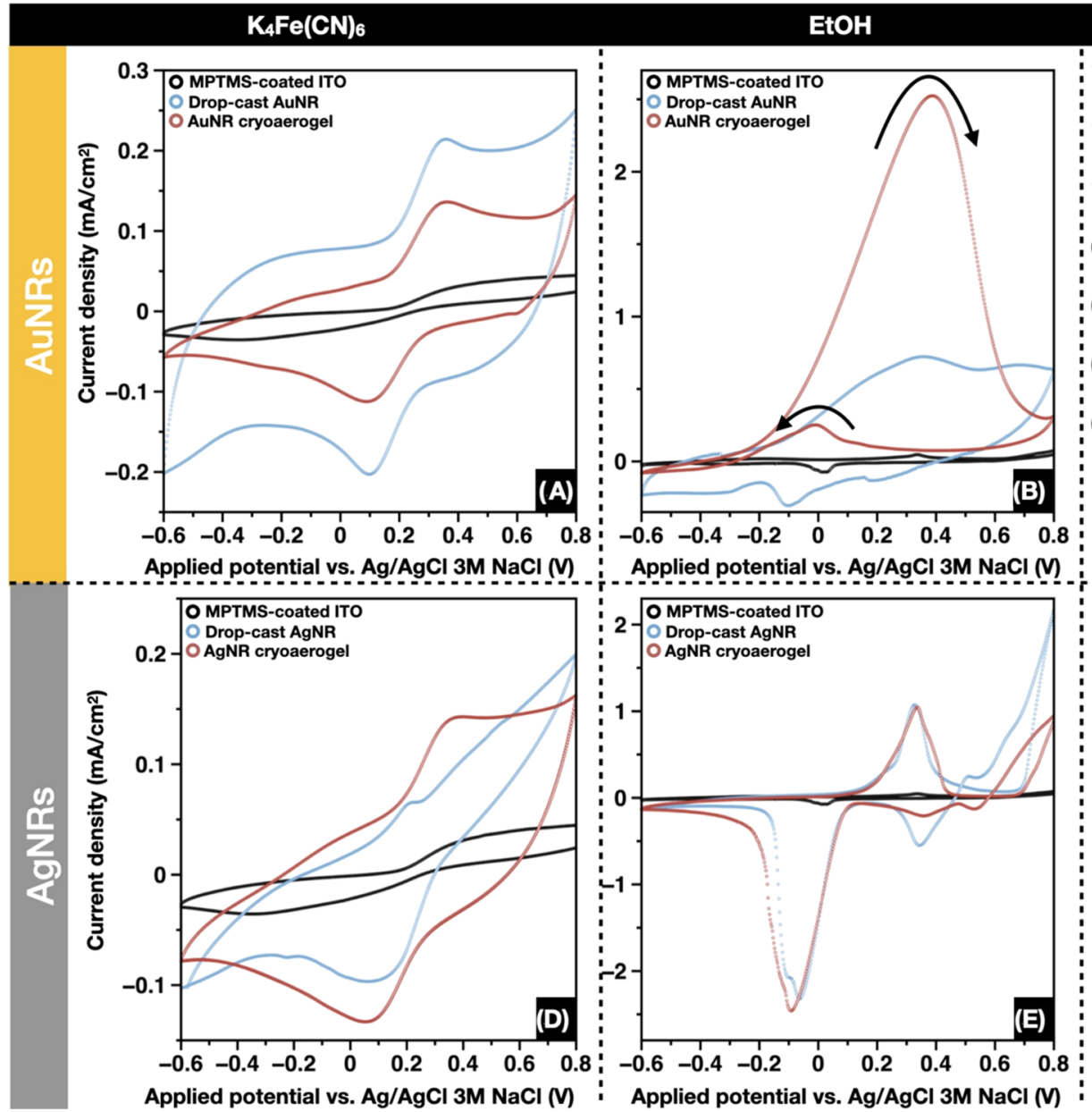

D-glucose
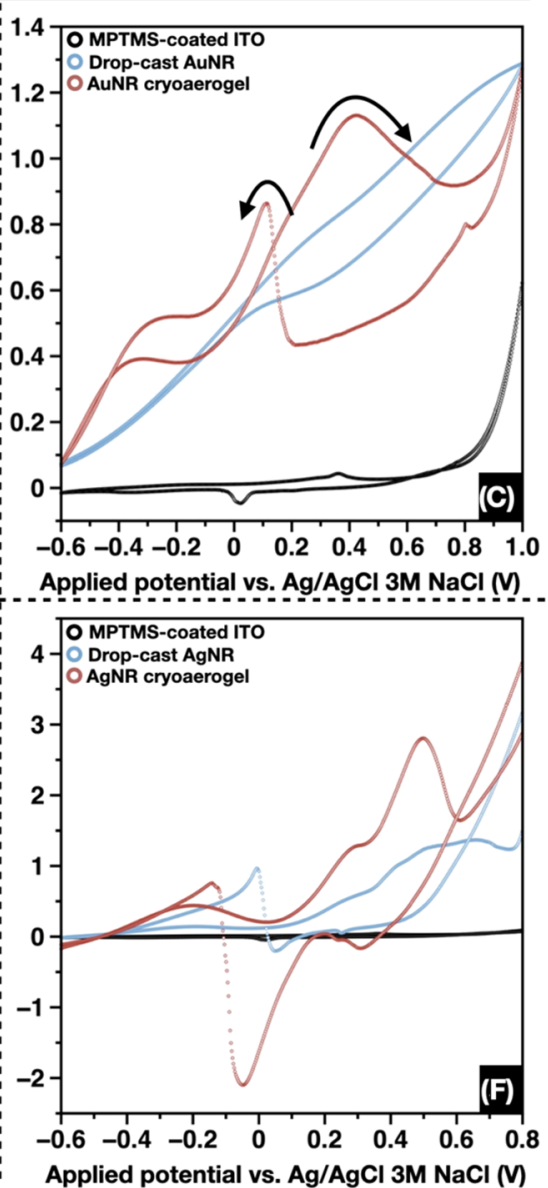

Figure 5. Comparative cyclic voltammograms of AuNR-based (A-C) and AgNR-based (D-F) electrodes in the redox sensing of 1 mM $\mathrm{K}_{4}\left[\mathrm{Fe}(\mathrm{CN})_{6}\right]$ in $\mathrm{pH}=7$ buffer $(\mathrm{A}, \mathrm{D})$, ethanol oxidation reaction (1 M EtOH in $\left.0.3 \mathrm{M} \mathrm{KOH}\right)(\mathrm{B}, \mathrm{E})$, and glucose sensing (100 mM D-glucose in $0.3 \mathrm{M} \mathrm{KOH})(\mathrm{C}, \mathrm{F})$. Blue curves represent the CV response of drop-cast and ambient dried NRs, while red CVs show the response of the NRbased cryoaerogel coatings.

show a more complex response in the presence of $\mathrm{OH}^{-}$due to the bimetallic nature of the AgNRs (with embedded AuBPs in each NR). Similar to the AuNRs, first, the formation of the first layers and multilayer of $\mathrm{Ag}_{2} \mathrm{O}$ appears in the anodic scan (peaks I and II), which can be accompanied by the partial oxidation of the AuBP cores. $\mathrm{Ag}_{2} \mathrm{O}$ as well as $\mathrm{Ag}^{0}$ can further be oxidized to $\mathrm{AgO}$ at higher positive bias potentials (peak III). Both types of silver oxides are reduced during the cathodic scan: first, the autocatalytic oxidation of $\mathrm{Ag}_{2} \mathrm{O}$ to $\mathrm{AgO}$ appears (peak IV), which is followed by the reduction of $\mathrm{AgO}$ to $\mathrm{Ag}_{2} \mathrm{O}$ (peak V). ${ }^{57}$ Peak VI includes the final reduction of $\mathrm{Ag}_{2} \mathrm{O}$ to $\mathrm{Ag}^{0}$, the reduction of gold oxide, as well as the desorption of $\mathrm{OH}^{-}$from the surface. As it is reflected by the $\mathrm{CV}$ response, silver is sensitive to oxidation and the multistep oxidation and reduction are expected to have a dramatic effect on the morphology of the building blocks. While the electrochemical stripping reaction (discussed above) does not lead to a stable system and causes a continuous evolution of the anodic and cathodic peaks, the electrochemical oxidation and reduction in $\mathrm{KOH}$ electrolyte lead to an equilibrium even after the 10th CV cycle: the response remains similar up to 50 cycles (corresponding to a treatment time of $1 \mathrm{~h}$ ). Based on the reduction peak of the metal oxides in the cathodic scan, the electrochemically active surface areas were estimated and found to be 5 and $34 \mathrm{~m}^{2} / \mathrm{g}$ for AuNR and AgNR cryoaerogels, respectively (details can be found in the SI).

The structure and composition of the cryoaerogel-coated electrodes were studied after 50 cycles of $\mathrm{CV}$ in $\mathrm{KOH}$ electrolyte. Figure S11 compares the microstructure of the cryoaerogel electrodes before and after the electrochemical oxidation/reduction in $\mathrm{KOH}$. Although the cryoaerogel consisting of AuNRs remained porous after the oxidative treatment, the nanorods fused together and lost their original shape (Figure S12). Nonetheless, the effect of oxidative treatment was more pronounced for the AgNR cryoaerogel. Due to the bimetallic nature of the NRs, the oxidation and redeposition of $\mathrm{Ag}^{0}$ induced the segregation of $\mathrm{Ag}$ - and $\mathrm{Au}$-rich areas clearly presented in the SEM images and EDX maps of Figure S13. While silver was redeposited in the form of larger AgNPs (with the size of several hundreds of nanometers), gold bipyramids remained almost intact and accumulated at certain areas on the electrode. A similar effect of electrooxidation on the morphology and composition was also found for the dropcast and ambient dried films (Figures S14-S16). This finding also indicates that silver is less stable from an electrochemical point of view, and neither the original nano- and microstructure nor the porosity can be preserved upon oxidative treatment. 
2.3.3. Redox Sensing and Electrocatalysis. Based on the availability of the active metal sites demonstrated in alkaline $\mathrm{pH}$ as well as in the presence of $\mathrm{Cl}^{-}$, the performance of the cryoaerogel coatings was tested in three model redox sensing reactions. To ensure the stability of the $\left[\mathrm{Fe}(\mathrm{CN})_{6}\right]^{4+} /$ $\left[\mathrm{Fe}(\mathrm{CN})_{6}\right]^{3+}$ cation, redox pair reactions were studied at a constant neutral $\mathrm{pH}$ ( $\mathrm{pH}=7$ buffer). Due to the superiority of alkaline $\mathrm{pH}$ in the oxidation of ethanol and glucose and the trends of the modern liquid fuel cells using alkaline $\mathrm{pH}$ resistant membranes, EOR and glucose sensing reactions were performed in $0.3 \mathrm{M} \mathrm{KOH}^{58-60}$

The MPTMS-coated ITO electrodes and the drop-cast (ambient dried) NR films were used to evaluate the influence of the cryoaerogel structures on the efficiency of the electrochemical sensing and electrocatalytic reactions. Figure 5 shows the cyclic voltammograms of the NR cryoaerogelcoated electrodes, the drop-cast NR films, as well as the MPTMS-coated ITO in the presence of $\mathrm{K}_{4}\left[\mathrm{Fe}(\mathrm{CN})_{6}\right]$ (in $\mathrm{pH}$ $=7$ buffer), $\mathrm{EtOH}$ (in $0.3 \mathrm{M} \mathrm{KOH}$ ), and D-glucose (in $0.3 \mathrm{M}$ $\mathrm{KOH})$.

As a model system for monitoring the interfacial electron transfer, the redox pair of ferrocyanide/ferricyanide was employed. Cryoaerogel coatings of AuNRs and AgNRs show the characteristic oxidation peak and reduction peak of the $\left[\mathrm{Fe}(\mathrm{CN})_{6}\right]^{4-} /\left[\mathrm{Fe}(\mathrm{CN})_{6}\right]^{3-}$ system in the anodic and cathodic scans, respectively. While the electron transfer is entirely hindered for MPTMS-coated ITO electrodes (without deposited NRs on its surface) due to the grafted MPTMS layer, cryoaerogels and NR films show prominent activity (Figure 5A,D). Both AuNR cryoaerogel and ambient dried film have similar voltammograms showing the same peak positions as well as peak-to-peak separation indicating similar behavior. The same peak-to-peak separation value $\left(\Delta E_{\mathrm{p}}=240 \mathrm{mV}\right)$ implies that the diffusion is not significantly impeded in the highly porous cryoaerogel coating compared to the flat and compact film of NRs. Although this value is larger than that of the bare ITO electrode (Figure S7A), the AuNR cryoaerogel increased the conductivity of the MPTMS-coated ITO electrode significantly, allowing the redox reaction to take place on the surface of the NRs. AgNR-based cryoaerogel shows similar behavior to the AuNR-based one; however, the dramatically increased electron transfer rate is clearly visible for the cryoaerogel coating in contrast to the simply dried film (Figure 5D).

The electrodes were also tested in ethanol oxidation reaction in alkaline medium. While the drop-cast AuNR film shows solely negligible performance in the EOR, the oxidation of ethanol is pronounced both in the anodic and cathodic scans for the AuNR cryoaerogel coating (Figure 5B). The strong anodic peak centered at $+380 \mathrm{mV}$ can be attributed to the first oxidation steps of EtOH to acetaldehyde and acetic acid. In the cathodic scan, the oxidation of the freshly diffusing alcohol appears at $-10 \mathrm{mV}$, which is less prominent due to the simultaneous oxidation of gold. ${ }^{61}$ In contrast, neither the dropcast AgNR film nor the AgNR cryoaerogel coating shows activity in the EOR (Figure $5 \mathrm{E}$ ), which indicates either the available crystal facets of AgNRs are not active in this specific catalytic reaction or the NRs lose their active facets due to their instability in alkaline medium as we have shown above.

Interestingly enough, the redox reaction of D-glucose can take place in the case of both AuNR and AgNR-based cryoaerogels. This implies that the surface sites of gold and silver NRs are still active for the glucose/dehydrogenated glucose/gluconolactone transition (anodic scan) ${ }^{62}$ as well as the reoxidation of glucose (cathodic scan), which indicates that the redeposited AgNPs do not lose their electrocatalytic activity for this specific reaction. It can be seen for both NRbased systems that the simply drop-cast films are entirely or partially inactive for glucose oxidation (Figure 5C,F). This observation underlines the benefit of the cryoaerogel formation endowing the gel structures with significantly larger electrocatalytic activity. It has to be noted, however, that glucose shows more distinct redox transitions in the case of the AuNR cryoaerogel structure. Besides the fact that gold hydroxide is also active in glucose oxidation, ${ }^{63}$ this indicates that the oxidation of silver is much more prominent at alkaline $\mathrm{pH}$ and AuNRs are more stable in the gel structure than the AgNRs. This also correlates with the peak-to-peak separation of the anodic and cathodic oxidation of glucose: the electron transfer is significantly more hindered for silver NRs compared to AuNRs. Additionally, the size difference between the two types of nanorods might also affect the activity negatively for the AgNRs due to their larger size. However, the synthesis of shorter AgNRs cannot be performed reliably due to shape purity issues emerging in the synthesis of smaller AuBPs.

Summarizing this subsection, redox model reactions demonstrated that cryoaerogel coatings drastically increased the efficiency of electron transfer compared to the MPTMScoated ITO substrates, and show activity in glucose sensing reaction. Additionally, the AuNR cryoaerogel coating has enhanced performance in the EOR. Besides the presence of electrocatalytic active sites, these results also show the advantages gained upon the fabrication of a highly porous macrostructure from the building blocks.

2.3.4. Electrochemical Impedance Spectroscopy. Nyquist plots of the electrochemical impedance spectroscopy results give more insights into the interfacial electron transfer between the electrolyte, cryoaerogel, and electrode surface. Figure 6 shows the EIS Nyquist plots of the MPTMS-coated ITO electrodes (Figure 6A) and the cryoaerogel-coated electrodes consisting of AuNRs and AgNRs (Figure 6B) in $0.3 \mathrm{M} \mathrm{KOH}$. The measurement data were fitted by the equivalent circuit method using modified Randle's cells shown in the inset of the impedance spectra. In all cases, the fitted equivalent circuits contain constant phase elements representing a certain degree of inhomogeneity, which makes the electrodes nonideal in terms of capacitive behavior. The fitted parameters are listed in Table 1.

As the EIS response in Figure 6A shows, the grafted MPTMS layer introduces a significant barrier between the ITO surface and the electrolyte manifesting in a steep quasi-linear tail region at smaller frequencies.

As the fitted values for the MPTMS-coated ITO's Randle circuit demonstrate, the overall resistance reaches the value of ca. $10^{6}-10^{8} \Omega$, showing the drastic influence of the MPTMS layer. As expected, the ohmic resistance of the electrolyte $\left(R_{\mathrm{s}}\right)$ is similar for the three systems; thus, it is unaffected by the deposition of the cryoaerogel coating. The fitted circuits contain two main further resistances representing the contribution of the ITO/electrolyte and the layer/electrolyte interfaces (where the layer consists of the MPTMS monolayer or the cryoaerogel coating on the MPTMS layer). The former $\left(R_{1}\right)$ decreases upon the formation of the nanorod cryoaerogels, which also supports the conclusions of the $\mathrm{CV}$ measurements above: compared to MPTMS-coated ITO, the resistance decreases with factors of 35 and 2.5 for AuNR and 


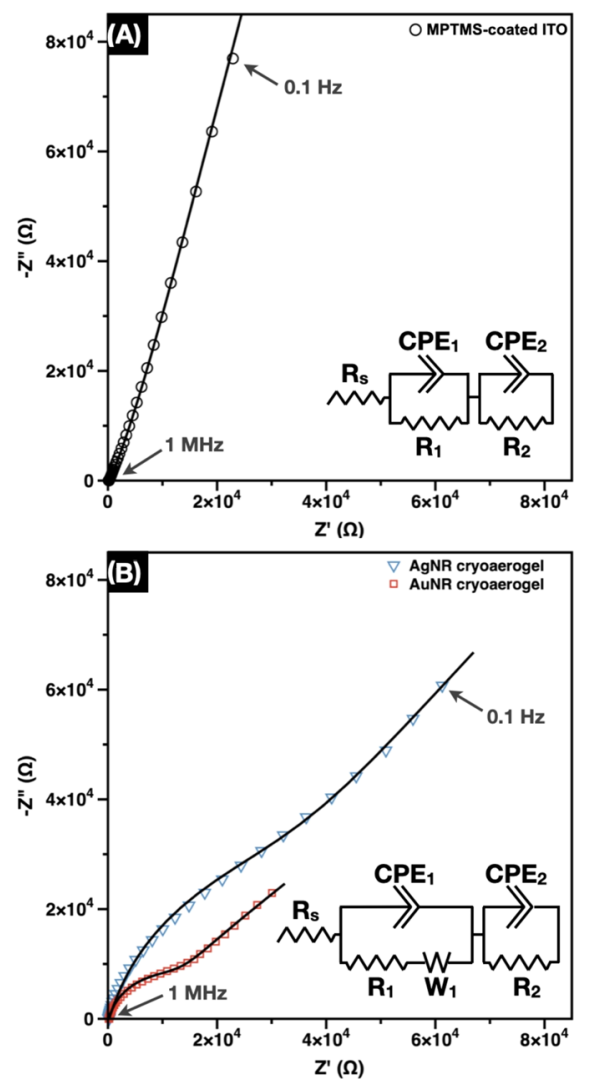

Figure 6. Electrochemical impedance spectra of MPTMS-coated ITO (A) and cryoaerogel coatings prepared from AuNRs and AgNRs (B) recorded in the frequency range of $0.1 \mathrm{~Hz}-1 \mathrm{MHz}$. For all of the measurements, $0.3 \mathrm{M} \mathrm{KOH}$ was used as an electrolyte. The insets represent the corresponding equivalent circuit models used for the fitting (solid black curves) of the experimental data.

AgNR cryoaerogels, respectively. This indicates that the electron transfer between the ITO and the electrolyte becomes prominently easier due to the conductive, rehydrated aerogel layer. The fitted Randle circuits also contain a second resistance $\left(R_{2}\right)$, which can be assigned to the classical charge transfer resistance, ${ }^{64}$ namely, the electron transfer at the electrolyte side of the coatings. This resistance can be dramatically suppressed upon the cryoaerogel formation with even 4 orders of magnitude. The experimental data of the cryoaerogel-coated electrodes can solely be fitted with Randle circuits containing a Warburg (W) impedance, which represents the contribution of the diffusion of the electrolyte ${ }^{65}$ into the porous structure. The values of $W$ show similar behavior in the terms of diffusion for both nanorod cryoaerogel structures implying a similar porosity and pore structure.

The results of the electrochemical impedance spectroscopy measurements imply that the formation of noble-metal cryoaerogel coatings on MTPS-coated ITO substrate endows the electrodes with significantly decreased overall resistance and enhanced electron transfer abilities. Additionally, the electrolyte can easily penetrate into the porous aerogel structure (due to its open-pore structure), facilitating the electrochemical processes on the active sites of the building blocks. This underlines their superior properties over their drop-cast counterparts in electrocatalytic applications.

\section{CONCLUSIONS}

The fabrication of cryoaerogel-coated electrodes consisting of AuNRs and $\mathrm{Au}$ bipyramid-templated AgNRs for electrocatalytic purposes was demonstrated. The fine-tuned and upscaled syntheses as well as the surface modification procedure of the building blocks overcame the concentration limitations of the use of noble-metal nanorods; thus, highly concentrated, stable nanorods with narrow size distribution were obtained. Using flash freezing and subsequent freeze drying, macroscopic cryoaerogel structures with dendritic pore structure and open porosity were fabricated on a conductive substrate. Electrochemical redox reactions (investigated via cyclic voltammetry) in the presence of $\mathrm{Cl}^{-}$and $\mathrm{OH}^{-}$revealed that the surface sites of the noble-metal nanorods in both types of cryoaerogel coatings are electrochemically available. It is shown furthermore that the applied conductive polymer (PEDOT:PSS) ligand shell does not hinder the electrooxidation and electrochemical stripping of the noble-metal surfaces. Although the electrooxidative treatment affected the structure of the cryoaerogel for both building blocks, the porosity for cryoaerogels of AuNRs was partially retained, while the AgNRs lost their original morphology. Besides the dissolution and recrystallization of Ag shell, the Au bipyramid core particles remained intact, which underlines the lower electrochemical stability of the silver shell. This reason also led to a different electrocatalytic activity in sensing test reactions: while AgNR cryoaerogels show limited response, AuNR cryoaerogels proved to be active in the redox detection $\mathrm{Fe}(\mathrm{CN}){ }_{6}^{3+/ 4+}$ and D-glucose as well as in ethanol oxidation reaction. Due to their porous structure, the cryoaerogels exceeded the performance of the simply dried, drop-cast counterparts significantly. Electrochemical impedance spectroscopy revealed a decreased overall resistance of the ITO/ MPTMS/cryoaerogel structures, facilitating a more effective electron transfer between the substrate and the electrolyte through the nanostructured aerogel coatings. This work foreshadows that noble-metal nanorods can be effectively used as electrocatalytic building blocks (or even template particles) in diverse assembled, porous macrostructures.

\section{EXPERIMENTAL SECTION AND METHODS}

4.1. Chemicals. Hydrogen tetrachloroaurate trihydrate $\left(\mathrm{HAuCl}_{4}\right.$. $3 \mathrm{H}_{2} \mathrm{O},>99.9 \%$ trace-metal basis), hexadecyltrimethylammonium

\section{Table 1. Fitted Parameters of the Electrochemical Impedance Spectra ${ }^{a}$}

\begin{tabular}{lccccccccc}
\multicolumn{1}{c}{ sample } & $R_{\mathrm{s}}[\Omega]$ & $R_{1}[\Omega]$ & $R_{2}[\Omega]$ & $\mathrm{CPE}_{1}[\mathrm{~F}]$ & $n_{1}$ & $\mathrm{CPE}_{2}[\mathrm{~F}]$ & $n_{2}$ & $W_{\mathrm{OR}}\left[\Omega s^{-1 / 2}\right]$ & $W_{\mathrm{OC}}[\mathrm{s}]^{b}$ \\
MPTMS-coated ITO & 195 & $9.99 \times 10^{5}$ & $4.32 \times 10^{8}$ & $2.75 \times 10^{-5}$ & 1.00 & $2.58 \times 10^{-5}$ & 0.67 & \\
AuNR cryoaerogel & 199 & $2.85 \times 10^{4}$ & $1.29 \times 10^{4}$ & $2.75 \times 10^{-5}$ & 0.87 & $5.54 \times 10^{-6}$ & 0.86 & $1.76 \times 10^{4}$ & 5.27 \\
AgNR cryoaerogel & 198 & $4.0 \times 10^{5}$ & $2.74 \times 10^{4}$ & $1.66 \times 10^{-5}$ & 0.73 & $7.90 \times 10^{-6}$ & 0.88 & $3.49 \times 10^{4}$ & 1.10
\end{tabular}

${ }^{a} R$ is the Ohmic resistance, $C P E$ is the constant phase element (having an exponent $0<n \leq 1$ ), and $W_{\mathrm{O}}$ is the open Warburg element consisting of two parameters: $W_{\mathrm{OR}}$ and $W_{\mathrm{OC}} \cdot{ }^{b} \mathrm{~W}_{\mathrm{OC}}$ is the parameter of the Warburg Open element and gives insights into the diffusion as follows: $W_{\mathrm{OC}}=$ $\mathrm{dD}^{-1 / 2}$, where $d$ is the Nernst diffusion layer thickness $[\mathrm{m}]$ and $D$ is the diffusion coefficient $\left[\mathrm{m}^{2} \mathrm{~s}^{-1}\right]$. 
bromide (CTAB, BioXtra, $\geq 99.0 \%$ ), hexadecyltrimethylammonium chloride (CTAC, 25wt \% in $\mathrm{H}_{2} \mathrm{O}$ ), $n$-decanol (98\%), L-ascorbic acid (AA, BioXtra, $\geq 99.0 \%$ ), sodium borohydride ( $\mathrm{NaBH} 4$, ReagentPlus, 99\%), silver nitrate (AgNO3, >99.0\%, ACS Reagent), hydrochloric acid ( $\mathrm{HCl}, 37$ wt \% in $\mathrm{H}_{2} \mathrm{O}, 99.999 \%$, trace-metal basis), poly $(3,4-$ ethylenedioxythiophene)-poly(styrenesulfonate), (PEDOT:PSS, 3.04.0 wt $\%$ in $\mathrm{H}_{2} \mathrm{O}$, high conductivity grade), acetone (puriss. p.a., ACS Reagent, $\geq 99.5 \%$ ), 2-propanol (puriss. p.a., ACS Reagent, $\geq 99.8 \%$ ), toluene (puriss. p.a., ACS Reagent, $\geq 99.7 \%$ ), hydrogen peroxide $\left(\mathrm{H}_{2} \mathrm{O}_{2}, 30 \%(\mathrm{w} / \mathrm{w})\right.$, puriss. p.a.), $\mathrm{NH}_{4} \mathrm{OH}$ solution (ACS Reagent, 28-30\% $\mathrm{NH}_{3}$ basis), 3-(mercaptopropyl)trimethoxysilane (MPTMS, 95\%), 2-methylbutane (isopentane, ReagentPlus, $\geq 99.0 \%$ ), potassium hydroxide (KOH, ACS reagent, $\geq 85 \%$, pellets), $\mathrm{D}-(+)$-glucose monohydrate $(\geq 99.5 \%)$, potassium chloride (KCl, ACS Reagent, $\geq 99.0 \%)$, potassium hexacyanoferrate(II) trihydrate $\left(\mathrm{K}_{4} \mathrm{Fe}(\mathrm{CN})_{6}\right.$, and ReagentPlus, $\geq 98.5 \%$ ) were purchased from Sigma-Aldrich. Ethanol (EtOH, ROTIPURAN, $\geq 99.8 \%$ ) and $\mathrm{pH} 7$ buffer (Roti Calipure, $\left.\mathrm{pH}=7.00 \pm 0.02\left(20^{\circ} \mathrm{C}\right)\right)$ were supplied by Roth. Tindoped indium oxide (ITO) coated soda lime float glass (thickness: 1.1 $\mathrm{mm}$, ITO surface resistance: $12 \mathrm{Ohm}$ per square) was purchased from VisionTek Ltd.

4.2. Synthesis of Gold Nanorods. 4.2.1. Preparation of CTAB/ $n$-Decanol Solution. CTAB $/ n$-decanol $(50 \mathrm{mM}: 13.5 \mathrm{mM})$ solution is prepared by dissolving $\mathrm{CTAB}(9.111 \mathrm{~g})$ in $500 \mathrm{~mL}$ of Millipore water in the presence of $n$-decanol $(1.288 \mathrm{~mL})$ under stirring at $60{ }^{\circ} \mathrm{C}$ for 1 $\mathrm{h}$. For complete dissolution, the solution is further stirred at room temperate for $16 \mathrm{~h}$ (overnight). The solution is kept at $27^{\circ} \mathrm{C}$ in an oven; thus, the recrystallization of CTAB can be fully avoided.

4.2.2. Synthesis of 1-2 $\mathrm{nm}$ Gold Seeds. Singe-crystal Au seeds are synthesized by following the method of González-Rubio et al. ${ }^{48}$ Precursor solution of $\mathrm{HAuCl}_{4} \cdot 3 \mathrm{H}_{2} \mathrm{O}(50 \mathrm{mM}, 100 \mu \mathrm{L})$ is dissolved in $\mathrm{CTAB} / n$-decanol solution $(10 \mathrm{~mL})$ under stirring at room temperature. The $\mathrm{Au}^{3+}$ ions form an orange color complex with the CTAB molecules, which takes several minutes to dissolve. After the complex dissolved, the freshly prepared ascorbic acid solution $(100 \mathrm{mM}, 50$ $\mu \mathrm{L})$ is injected, and after the solution turns colorless, a freshly prepared $\mathrm{NaBH}_{4}$ solution $(0.02 \mathrm{M}, 400 \mu \mathrm{L}$, using room-temperature Millipore water) is swiftly injected under vigorous stirring. After $1 \mathrm{~min}$ of stirring, the seed solution is kept at $26^{\circ} \mathrm{C}$ for $1 \mathrm{~h}$ to age the seeds and to fully decompose the residual borohydride. Note that sodium borohydride is sensitive to moisture; thus, it is recommended to store it under an inert atmosphere in a glovebox.

4.2.3. Growth of Gold Nanorods. Gold nanorods are prepared by an upscaled and modified method based on González-Rubio et al. ${ }^{48}$ Precursor solution of $\mathrm{HAuCl}_{4} \cdot 3 \mathrm{H}_{2} \mathrm{O}(50 \mathrm{mM}, 3 \mathrm{~mL})$ is dissolved in $\mathrm{CTAB} / n$-decanol solution $(300 \mathrm{~mL})$ under stirring at room temperature. After the complex dissolved, $\mathrm{AgNO}_{3}$ solution $(10 \mathrm{mM}$, $2.4 \mathrm{~mL}), \mathrm{HCl}(1 \mathrm{M}, 21 \mathrm{~mL})$, and $\mathrm{AA}(100 \mathrm{mM}, 3.9 \mathrm{~mL})$ are added subsequently under stirring. After the solution turns colorless, the solution of presynthesized Au seeds $(1.8 \mathrm{~mL})$ is injected rapidly, and the stirring is continued for a further $30 \mathrm{~s}$. Afterward, the stirring bar is removed and the solution is kept at $25{ }^{\circ} \mathrm{C}$ overnight for the growth of the nanorods.

4.3. Synthesis of Silver Nanorods. 4.3.1. Synthesis of Pentatwinned Gold Seeds. Pentatwinned Au seeds are synthesized using the method of $\mathrm{Li}$ et al. ${ }^{51}$ Precursor solution of $\mathrm{HAuCl}_{4} \cdot 3 \mathrm{H}_{2} \mathrm{O}$ $(25 \mathrm{mM}, 200 \mu \mathrm{L})$ and sodium citrate solution $(50 \mathrm{mM}, 2 \mathrm{~mL})$ are dissolved in CTAC solution $(60.6 \mathrm{mM}, 16.5 \mathrm{~mL})$ under stirring in a water bath tempered at $30{ }^{\circ} \mathrm{C}$. The solution is gently stirred for 10 min followed by the swift addition of the ice-cold $\mathrm{NaBH}_{4}$ solution (10 $\mathrm{mM}, 1.2 \mathrm{~mL}$, freshly prepared) under vigorous stirring. After $1 \mathrm{~min}$ of stirring, the stirring bar is removed and the solution is kept undisturbed at $40{ }^{\circ} \mathrm{C}$ in an oven for 5 days to induce the twin plane formation of the original single-crystal seeds. The formation of the pentatwinned seeds is also visible to the eye: the solution turns red, and a prominent LSPR peak evolves (centered at $516 \mathrm{~nm}$ ).

4.3.2. Synthesis of Gold Bipyramids. Pentatwinned Au seeds are used to grow gold bipyramids using an upscaled protocol of $\mathrm{Li}$ et al. ${ }^{51}$ In a $500 \mathrm{~mL}$ bottle, precursor solution of $\mathrm{HAuCl}_{4} \cdot 3 \mathrm{H}_{2} \mathrm{O}(25 \mathrm{mM}, 4$ $\mathrm{mL}), \mathrm{AgNO}_{3}$ solution $(10 \mathrm{mM}, 2 \mathrm{~mL}), \mathrm{HCl}$ solution $(1 \mathrm{M}, 4 \mathrm{~mL})$, and $\mathrm{AA}$ solution $(100 \mathrm{mM}, 1.6 \mathrm{~mL})$ are sequentially added to CTAB solution $(100 \mathrm{mM}, 200 \mathrm{~mL})$ under stirring at $30^{\circ} \mathrm{C}$. After obtaining a colorless solution, pentatwinned seeds $(1.8 \mathrm{~mL})$ are added under stirring, the stirring bar is removed, and the solution is kept in an oven at $30{ }^{\circ} \mathrm{C}$ for $4 \mathrm{~h}$ and afterward at room temperature overnight. The bipyramids show a strong longitudinal LSPR at $726 \mathrm{~nm}$. The solution is concentrated by centrifugation using $50 \mathrm{~mL}$ Falcon tubes $(8000 \mathrm{rcf}$, $30 \mathrm{~min}$ ), the supernatant is discarded, and the precipitates are merged $(V \cong 6 \mathrm{~mL})$. This is further centrifuged in Eppendorf tubes $(4 \times 1.5$ $\mathrm{mL}, 8000 \mathrm{rcf}, 20 \mathrm{~min})$, and the precipitate is redispersed in $4 \times 1.4$ $\mathrm{mL}$ CTAC $(10 \mathrm{mM})$. This step is repeated once more, and the bipyramids are redispersed in CTAC ( $7 \mathrm{~mL}$ in total, $10 \mathrm{mM})$. After determining the concentration of $\mathrm{Au}$ in the concentrated bipyramid solution, the solution is diluted with CTAC $(10 \mathrm{mM})$ to reach the final $\mathrm{Au}^{0}$ concentration of $0.125 \mathrm{mM}$ and stored at room temperature in a dark place for further processing.

4.3.3. Growth of Silver Nanorods. Gold bipyramids are used as seeds for growing the silver nanorods using a slightly modified procedure based on Sánchez-Iglesias et al. ${ }^{49}$ Gold bipyramid solution $\left(0.125 \mathrm{mM}\right.$ in terms of $\mathrm{Au}^{0}$ in $10 \mathrm{mM}$ CTAC, $\left.200 \mathrm{~mL}\right)$ is mixed with $\mathrm{AgNO}_{3}$ solution $(10 \mathrm{mM}, 6.2 \mathrm{~mL})$ under stirring in a water bath tempered at $60{ }^{\circ} \mathrm{C}$. AA solution $(100 \mathrm{mM}, 2.48 \mathrm{~mL})$ is added, and the reaction proceeds for $1 \mathrm{~h}$ at $60{ }^{\circ} \mathrm{C}$ under mild stirring. Numerous gradual color changes take place upon the growth: the color turns from brownish to green, later to yellowish-green, and finally to orange when the growth is complete. After the removal of the stirring bar, the solution is let cool down to room temperature.

4.3.4. Purification and Concentration of AuNRs and AgNRs. The nanorod solutions are centrifuged in $50 \mathrm{~mL}$ Falcon tubes $(12000 \mathrm{rcf}$ $\times 80 \mathrm{~min}$ for AuNRs, $6000 \mathrm{rcf} \times 25 \mathrm{~min}$ for AgNRs). The collected supernatants are centrifuged again under the same conditions. The precipitates are merged $(V \cong 5 \mathrm{~mL})$ and topped up to $18 \mathrm{~mL}$ using Millipore water. These solutions are divided into 12 Eppendorf tubes $(1.5 \mathrm{~mL}$ to each) and centrifuged again $(10000 \mathrm{rcf} \times 45 \mathrm{~min}$ for AuNRs, $6000 \mathrm{rcf} \times 30 \mathrm{~min}$ for AgNRs). The supernatants are collected and centrifuged again. Millipore water $(1.3 \mathrm{~mL}$ to each tube) was added to the merged precipitates, and the centrifuging step is repeated. Finally, the particles are redispersed in a total of $c a .2 \mathrm{~mL}$ of water $\left(V_{\text {total }} \cong 2.5 \mathrm{~mL}\right)$.

4.3.5. Surface Modification of the Nanorods with PEDOT:PSS. The CTAC ligands of the nanorods are replaced by PEDOT:PSS by following the protocol of Zhang et al. ${ }^{53}$ Aqueous PEDOT:PSS solution $(45 \mathrm{~mL}, 0.9 \mathrm{~g} / \mathrm{L})$ is prepared by diluting $1.145 \mathrm{~mL}$ of PEDOT:PSS stock solution (3-4 wt \% in $\mathrm{H}_{2} \mathrm{O}$ as it is received from Sigma-Aldrich) with Millipore water. Under vigorous stirring, the concentrated nanorod solution $(V \cong 2.5 \mathrm{~mL})$ is swiftly injected into the PEDOT:PSS solution at room temperature. The solution is gently stirred for $16 \mathrm{~h}$. Afterward, the particles are further processed as follows.

4.3.6. Purification and Final Concentration of Nanorods for Cryogelation. The excess of PEDOT:PSS is removed via centrifugation (first in $50 \mathrm{~mL}$ Falcon tubes, $9000 \mathrm{rcf} \times 40 \mathrm{~min}$ for AuNRs, $6000 \mathrm{rcf} \times 15 \mathrm{~min}$ for AgNRs). The blue supernatant is discarded, and the precipitate is further washed in Eppendorf tubes as described above for the nonmodified NRs. In a further centrifuging step, the particles are concentrated to reach the final noble-metal concentrations $\left(c\left(\mathrm{Au}^{0}\right)=8.8 \mathrm{~g} / \mathrm{L}, c\left(\mathrm{Au}^{0}+\mathrm{Ag}^{0}\right)=5.4 \mathrm{~g} / \mathrm{L}\right.$; determined by atomic absorption spectroscopy). This solution is used for the cryoaerogel preparation detailed below.

4.4. Preparation of Cryoaerogel Electrodes. 4.4.1. Functionalization of ITO-Coated Glass Slides. First, the ITO-coated glass is cut into rectangles $(15 \mathrm{~mm} \times 30 \mathrm{~mm})$. The slides are cleaned by subsequent ultrasonication in acetone, 2-propanol, and Millipore water for $10 \mathrm{~min}$ each. The surface is activated in $\mathrm{H}_{2} \mathrm{O}_{2} / \mathrm{NH}_{4} \mathrm{OH}$ solutions (1:1:5 volume ratio prepared from $30 \mathrm{wt} \% \mathrm{H}_{2} \mathrm{O}_{2}$ and $28-$ 32 wt \% $\mathrm{NH}_{4} \mathrm{OH}$ solution) under gentle stirring at $50{ }^{\circ} \mathrm{C}$ for $2 \mathrm{~h}$. After rinsing with Millipore water, 2-propanol, and toluene, the slides are functionalized in a toluene solution of MPTMS ( $2 \mathrm{v} / \mathrm{v} \%)$ under low stirring at $70{ }^{\circ} \mathrm{C}$ for $2 \mathrm{~h}$ followed by stirring at room temperature 
for further $24 \mathrm{~h}$. The slides are rinsed with toluene, dried with pressurized air, and stored in an oven at $50{ }^{\circ} \mathrm{C}$.

4.4.2. Molding. A rectangular mold from adhesive tape (TESA) is glued onto the MPTMS-coated ITO slides. The mold has an opening with the dimension of $5 \mathrm{~mm} \times 5 \mathrm{~mm}$, where the nanorod solutions are drop-cast in the next step.

4.4.3. Cryogelation and Freeze Drying. Into the opening of the mold, $5 \mu \mathrm{L}$ of concentrated NR@PEDOT:PSS solution is drop-cast and spread gently with the tip of the pipette to homogeneously fill the entire mold with the solution. Using tweezers, the slides are dipped into 2-methylbutane (isopentane, cooled to $113 \mathrm{~K}$ using liquid $\mathrm{N}_{2}$ ) for $10 \mathrm{~s}$ to flash-freeze the NR solution in the mold. Afterward, the slides are transferred to liquid $\mathrm{N}_{2}$ to keep them in the frozen state. Note that the work with cooled isopentane and liquid $\mathrm{N}_{2}$ requires special care due to the possible injury! Always wear cryogloves and use long tweezers to avoid freezing of your fingers! The slides are stored under liquid $\mathrm{N}_{2}$ overnight and dried in a freeze dryer (Martin Christ $\alpha 1-2$ LD Plus) at 0.06 mbar for $24 \mathrm{~h}$ to obtain the cryoaerogel-coated electrodes.

4.4.4. Electrochemical Measurements. The cryoaerogel-coated ITO samples are placed into the lab-designed electrochemistry cell and are slowly rehydrated by the electrolyte (or the analyte solution in the supporting electrolyte). Before the measurements, the sample is kept in the solution for $c a .10 \mathrm{~min}$ to reach the equilibrium and to let the electrolyte penetrate into the structure.

4.4.5. Cyclic Voltammetry. The measurements are carried out in a three-electrode setup consisting of a counter electrode ( $\mathrm{Pt}$ wire, $99.95 \%, 1.6 \mathrm{~mm}$ in diameter, $100 \mathrm{~mm}$ in length, Goodfellow), a reference electrode $(\mathrm{Ag} / \mathrm{AgCl}$ in $3 \mathrm{M} \mathrm{NaCl}$, purchased from $\mathrm{BASi})$, and a working electrode (cryoaerogels on ITO-coated glass) using a Metrohm Autolab PGSTA T204 potentiostat. The active area of the electrode is $0.196 \mathrm{~mm}^{2}$. The electrolyte solutions $(0.3 \mathrm{KOH}, 1 \mathrm{M}$ EtOH in $0.3 \mathrm{M} \mathrm{KOH}, 100 \mathrm{mM}$ D-glucose in $0.3 \mathrm{M} \mathrm{KOH}, 20 \mathrm{mM}$ $\mathrm{KCl}, \mathrm{pH} 7$ Roti Calipure buffer, and $1 \mathrm{mM} \mathrm{K}_{4}\left[\mathrm{Fe}(\mathrm{CN})_{6}\right]$ in $\mathrm{pH}=7$ buffer) are prepared freshly and purged with argon for $1 \mathrm{~h}$ before the measurements. The $\mathrm{CV}$ measurements are recorded using a scan rate of $50 \mathrm{mV} \mathrm{s}^{-1}$ for all of the experiments.

4.4.6. Electrochemical Impedance Spectroscopy. EIS measurements are performed in the same three-electrode setup described in the CV section using a Modulab XM ECS potentiostat from Solartron. After an equilibration time of $60 \mathrm{~s}$, the measurements are performed at $0 \mathrm{mV}$ DC potential with an AC modulation of $20 \mathrm{mV}$ in the frequency range of $0.1 \mathrm{~Hz}$ to $1 \mathrm{MHz}$. All of the experiments are carried out in $0.3 \mathrm{M} \mathrm{KOH}$ electrolyte.

4.5. Structural and Optical Investigations. 4.5.1. Scanning Electron Microscopy. SEM images of colloidal nanorods are recorded after drop-casting the NR solution onto Si wafers. Cryoaerogel-coated ITO slides are glued onto brass SEM holders using carbon pads and conductive silver lacquer. For imaging and EDX compositional analysis, a JEOL JFM 6700F scanning electron microscope equipped with an Oxford Instruments INCA 300 detector is used. The gun is operated at $2 \mathrm{kV}$ and $10 \mathrm{kV}$ for imaging and EDXS, respectively.

4.5.2. Transmission Electron Microscopy. TEM and HRTEM images are recorded with an FEI Tecnai G2 F20 TMP microscope operated at $200 \mathrm{kV}$. The nanorod solutions are drop-cast onto carboncoated copper grids (Quantifoil). Energy-dispersive X-ray spectroscopy (EDX) and high-angle annular dark-field scanning transmission electron microscopy (HAADF-STEM) measurements are performed with a JEOL JEM-2100F microscope equipped with a field emission gun operating at $200 \mathrm{kV}$.

4.5.3. UVNis/NIR Extinction and Absorption Measurements. $\mathrm{UV} /$ vis/NIR extinction spectra of the nanorod solutions are recorded in quartz cuvettes using an Agilent Cary 5000 spectrometer. Absorption spectra of the cryoaerogel-coated ITO glasses are recorded using a diffuse reflectance accessory (integrating sphere) of Cary 5000 using the center mount position.

\section{ASSOCIATED CONTENT}

\section{(s) Supporting Information}

The Supporting Information is available free of charge at https://pubs.acs.org/doi/10.1021/acsami.1c16424.

Results on the optimization of the synthesis of pentatwinned $\mathrm{Au}$ seeds, $\mathrm{Au}$ bipyramids, and $\mathrm{Ag}$ nanorods; extinction spectra of AuNRs and AgNRs before and after surface modification; long-term stability of AgNRs (HAADF-TEM images and EDX maps); optimization of the ITO functionalization ( $\mathrm{CV}$ curves); photographs and microscope images of cryoaerogels; chemical reactions associated with the $\mathrm{CV}$ peaks in $\mathrm{KCl}$ and $\mathrm{KOH}$ electrolytes; ECSA calculations; vis-NIR absorption spectra of cryoaerogels; SEM images and EDX elemental maps of AuNR and AgNR cryoaerogels as well as simply dried NR samples after $50 \mathrm{CV}$ cycles; and cyclic voltammograms of drop-cast and simply dried AuNR and AgNR electrodes (PDF)

\section{AUTHOR INFORMATION}

\section{Corresponding Author}

Nadja C. Bigall - Institute of Physical Chemistry and Electrochemistry, Leibniz Universität Hannover, 30519

Hanover, Germany; Cluster of Excellence PhoenixD

(Photonics, Optics and Engineering - Innovation Across

Disciplines), Leibniz Universität Hannover, 30167 Hanover, Germany; O orcid.org/0000-0003-0171-1106;

Email: nadja.bigall@pci.uni-hannover.de

\section{Authors}

Dániel Zámbó - Institute of Physical Chemistry and Electrochemistry, Leibniz Universität Hannover, 30519

Hanover, Germany; Centre for Energy Research, Institute of Technical Physics and Materials Science, 1121 Budapest, Hungary; (1) orcid.org/0000-0001-7671-039X

Pascal Rusch - Institute of Physical Chemistry and Electrochemistry, Leibniz Universität Hannover, 30519 Hanover, Germany

Franziska Lübkemann - Institute of Physical Chemistry and Electrochemistry, Leibniz Universität Hannover, 30519

Hanover, Germany; 이이.org/0000-0003-4783-0223

Complete contact information is available at:

https://pubs.acs.org/10.1021/acsami.1c16424

\section{Author Contributions}

The manuscript was written through contributions of all authors. All authors have given approval to the final version of the manuscript.

\section{Notes}

The authors declare no competing financial interest.

\section{ACKNOWLEDGMENTS}

The authors thank the financial support of the European Research Council (ERC) under the European Union's Horizon 2020 research and innovation program (grant agreement 714429). In addition, this work was funded by the German Research Foundation (Deutsche Forschungsgemeinschaft, DFG) under Germany's excellence strategy within the cluster of excellence PhoenixD (EXC 2122, project ID 390833453) and the grant BI 1708/4-1. The authors moreover thank the Laboratory of Nano and Quantum Engineering 
(LNQE) and Prof. Armin Feldhoff for providing the TEM facility.

\section{REFERENCES}

(1) Wang, L.; Hasanzadeh Kafshgari, M.; Meunier, M. Optical Properties and Applications of Plasmonic-Metal Nanoparticles. Adv. Funct. Mater. 2020, 30, No. 2005400.

(2) Sau, T. K.; Rogach, A. L.; Jäckel, F.; Klar, T. A.; Feldmann, J. Properties and Applications of Colloidal Nonspherical Noble Metal Nanoparticles. Adv. Mater. 2010, 22, 1805-1825.

(3) Azharuddin, M.; Zhu, G. H.; Das, D.; Ozgur, E.; Uzun, L.; Turner, A. P. F.; Patra, H. K. A Repertoire of Biomedical Applications of Noble Metal Nanoparticles. Chem. Commun. 2019, 55, 6964-6996.

(4) Singh, H.; Bamrah, A.; Bhardwaj, S. K.; Deep, A.; Khatri, M.; Brown, R. J. C.; Bhardwaj, N.; Kim, K.-H. Recent Advances in the Application of Noble Metal Nanoparticles in Colorimetric Sensors for Lead Ions. Environ. Sci.: Nano 2021, 8, 863-889.

(5) Dykman, L.; Khlebtsov, N. Gold Nanoparticles in Biomedical Applications: Recent Advances and Perspectives. Chem. Soc. Rev. 2012, 41, 2256-2282.

(6) Daniel, M.-C.; Astruc, D. Gold Nanoparticles: Assembly, Supramolecular Chemistry, Quantum-Size-Related Properties, and Applications toward Biology, Catalysis, and Nanotechnology. Chem. Rev. 2004, 104, 293-346.

(7) Shi, Y.; Lyu, Z.; Zhao, M.; Chen, R.; Nguyen, Q. N.; Xia, Y. Noble-Metal Nanocrystals with Controlled Shapes for Catalytic and Electrocatalytic Applications. Chem. Rev. 2021, 121, 649-735.

(8) Zijlstra, P.; Orrit, M. Single Metal Nanoparticles: Optical Detection, Spectroscopy and Applications. Rep. Prog. Phys. 2011, 74, No. 106401

(9) Habibullah, G.; Viktorova, J.; Ruml, T. Current Strategies for Noble Metal Nanoparticle Synthesis. Nanoscale Res. Lett. 2021, 16, No. 47.

(10) Boles, M. A.; Engel, M.; Talapin, D. V. Self-Assembly of Colloidal Nanocrystals: From Intricate Structures to Functional Materials. Chem. Rev. 2016, 116, 11220-11289.

(11) Brezesinski, T.; Groenewolt, M.; Gibaud, A.; Pinna, N.; Antonietti, M.; Smarsly, B. Evaporation-Induced Self-Assembly (EISA) at Its Limit: Ultrathin, Crystalline Patterns by Templating of Micellar Monolayers. Adv. Mater. 2006, 18, 2260-2263.

(12) Grzelczak, M.; Vermant, J.; Furst, E. M.; Liz-Marzán, L. M. Directed Self-Assembly of Nanoparticles. ACS Nano 2010, 4, 35913605.

(13) Stolarczyk, J. K.; Deak, A.; Brougham, D. F. Nanoparticle Clusters: Assembly and Control Over Internal Order, Current Capabilities, and Future Potential. Adv. Mater. 2016, 28, 5400-5424.

(14) Zámbó, D.; Radnóczi, G. Z.; Deák, A. Preparation of Compact Nanoparticle Clusters from Polyethylene Glycol-Coated Gold Nanoparticles by Fine-Tuning Colloidal Interactions. Langmuir 2015, 31, $2662-2668$

(15) Katiyar, P.; Singh, J. K. Evaporation Induced Self-Assembly of Different Shapes and Sizes of Nanoparticles: A Molecular Dynamics Study. J. Chem. Phys. 2019, 150, No. 044708.

(16) Zhang, Z.; Lin, M. High-Yield Preparation of Vertically Aligned Gold Nanorod Arrays via a Controlled Evaporation-Induced SelfAssembly Method. J. Mater. Chem. C 2014, 2, 4545.

(17) Rusch, P.; Zámbó, D.; Bigall, N. C. Control over Structure and Properties in Nanocrystal Aerogels at the Nano-, Micro-, and Macroscale. Acc. Chem. Res. 2020, 53, 2414-2424.

(18) Matter, F.; Luna, A. L.; Niederberger, M. From Colloidal Dispersions to Aerogels: How to Master Nanoparticle Gelation. Nano Today 2020, 30, No. 100827.

(19) Bigall, N. C.; Herrmann, A.-K.; Vogel, M.; Rose, M.; Simon, P.; Carrillo-Cabrera, W.; Dorfs, D.; Kaskel, S.; Gaponik, N.; Eychmüller, A. Hydrogels and Aerogels from Noble Metal Nanoparticles. Angew. Chem., Int. Ed. 2009, 48, 9731-9734.

(20) Liu, W.; Herrmann, A.-K.; Bigall, N. C.; Rodriguez, P.; Wen, D.; Oezaslan, M.; Schmidt, T. J.; Gaponik, N.; Eychmüller, A. Noble
Metal Aerogels-Synthesis, Characterization, and Application as Electrocatalysts. Acc. Chem. Res. 2015, 48, 154-162.

(21) Du, R.; Fan, X.; Jin, X.; Hübner, R.; Hu, Y.; Eychmüller, A. Emerging Noble Metal Aerogels: State of the Art and a Look Forward. Matter 2019, 1, 39-56.

(22) Zhang, R.; Zhao, Y. Preparation and Electrocatalysis Application of Pure Metallic Aerogel: A Review. Catalysts 2020, 10, 1376.

(23) Ziegler, C.; Wolf, A.; Liu, W.; Herrmann, A.-K.; Gaponik, N.; Eychmüller, A. Modern Inorganic Aerogels. Angew. Chem., Int. Ed. 2017, 56, 13200-13221.

(24) Georgi, M.; Klemmed, B.; Benad, A.; Eychmüller, A. A Versatile Ethanolic Approach to Metal Aerogels (Pt, Pd, $\mathrm{Au}, \mathrm{Ag}, \mathrm{Cu}$ and $\mathrm{Co}$ ). Mater. Chem. Front. 2019, 3, 1586-1592.

(25) Wang, H.; Fang, Q.; Gu, W.; Du, D.; Lin, Y.; Zhu, C. Noble Metal Aerogels. ACS Appl. Mater. Interfaces 2020, 12, 52234-52250.

(26) Naskar, S.; Freytag, A.; Deutsch, J.; Wendt, N.; Behrens, P.; Köckritz, A.; Bigall, N. C. Porous Aerogels from Shape-Controlled Metal Nanoparticles Directly from Nonpolar Colloidal Solution. Chem. Mater. 2017, 29, 9208-9217.

(27) Wen, D.; Liu, W.; Haubold, D.; Zhu, C.; Oschatz, M.; Holzschuh, M.; Wolf, A.; Simon, F.; Kaskel, S.; Eychmüller, A. Gold Aerogels: Three-Dimensional Assembly of Nanoparticles and Their Use as Electrocatalytic Interfaces. ACS Nano 2016, 10, 2559-2567.

(28) Freytag, A.; Sánchez-Paradinas, S.; Naskar, S.; Wendt, N.; Colombo, M.; Pugliese, G.; Poppe, J.; Demirci, C.; Kretschmer, I.; Bahnemann, D. W.; Behrens, P.; Bigall, N. C. Versatile Aerogel Fabrication by Freezing and Subsequent Freeze-Drying of Colloidal Nanoparticle Solutions. Angew. Chem., Int. Ed. 2016, 55, 1200-1203.

(29) Du, R.; Joswig, J.; Hübner, R.; Zhou, L.; Wei, W.; Hu, Y.; Eychmüller, A. Freeze-Thaw-Promoted Fabrication of Clean and Hierarchically Structured Noble-Metal Aerogels for Electrocatalysis and Photoelectrocatalysis. Angew. Chem. 2020, 132, 8370-8377.

(30) Demirci, C.; Marras, S.; Prato, M.; Pasquale, L.; Manna, L.; Colombo, M. Design of Catalytically Active Porous Gold Structures from a Bottom-up Method: The Role of Metal Traces in CO Oxidation and Oxidative Coupling of Methanol. J. Catal. 2019, 375, 279-286.

(31) Cai, B.; Dianat, A.; Hübner, R.; Liu, W.; Wen, D.; Benad, A.; Sonntag, L.; Gemming, T.; Cuniberti, G.; Eychmüller, A. Multimetallic Hierarchical Aerogels: Shape Engineering of the Building Blocks for Efficient Electrocatalysis. Adv. Mater. 2017, 29, No. 1605254.

(32) Alwin, S.; Sahaya Shajan, X. Aerogels: Promising Nanostructured Materials for Energy Conversion and Storage Applications. Mater. Renewable Sustainable Energy 2020, 9, No. 7.

(33) Jiang, B.; Wan, Z.; Kang, Y.; Guo, Y.; Henzie, J.; Na, J.; Li, H.; Wang, S.; Bando, Y.; Sakka, Y.; Yamauchi, Y. Auto-Programmed Synthesis of Metallic Aerogels: Core-Shell Cu@Fe@Ni Aerogels for Efficient Oxygen Evolution Reaction. Nano Energy 2021, 81, 105644. DOI: $10.1016 /$ j.nanoen.2020.105644

(34) Schmidt, T. J.; Gasteiger, H. A.; Stäb, G. D.; Urban, P. M.; Kolb, D. M.; Behm, R. J. Characterization of High-Surface-Area Electrocatalysts Using a Rotating Disk Electrode Configuration. J. Electrochem. Soc. 1998, 145, 2354-2358.

(35) Mao, J.; Wu, F.-F.; Shi, W.-H.; Liu, W.-X.; Xu, X.-L.; Cai, G.-F.; Li, Y.-W.; Cao, X.-H. Preparation of Polyaniline-Coated Composite Aerogel of $\mathrm{MnO} 2$ and Reduced Graphene Oxide for HighPerformance Zinc-Ion Battery. Chin. J. Polym. Sci. 2020, 38, 514-521. (36) Freytag, A.; Günnemann, C.; Naskar, S.; Hamid, S.; Lübkemann, F.; Bahnemann, D.; Bigall, N. C. Tailoring Composition and Material Distribution in Multicomponent Cryoaerogels for Application in Photocatalysis. ACS Appl. Nano Mater. 2018, 1, 6123-6130.

(37) Müller, D.; Zámbó, D.; Dorfs, D.; Bigall, N. C. Cryoaerogels and Cryohydrogels as Efficient Electrocatalysts. Small 2021, 17, No. 2007908. 
(38) Müller, D.; Klepzig, L. F.; Schlosser, A.; Dorfs, D.; Bigall, N. C. Structural Diversity in Cryoaerogel Synthesis. Langmuir 2021, 37, 5109-5117.

(39) Freytag, A.; Colombo, M.; Bigall, N. C. Catalytic Properties of Cryogelated Noble Metal Aerogels. Z. Phys. Chem. 2017, 231, 63-75.

(40) Schlosser, A.; Meyer, L. C.; Lübkemann, F.; Miethe, J. F.; Bigall, N. C. Nanoplatelet Cryoaerogels with Potential Application in Photoelectrochemical Sensing. Phys. Chem. Chem. Phys. 2019, 21, 9002-9012.

(41) Zhang, A.; Chen, Y.; Yang, Z.; Ma, S.; Huang, Y.; Richter, G.; Schützendübe, P.; Zhong, C.; Wang, Z. Enhanced Electrocatalytic Activities toward the Ethanol Oxidation of Nanoporous Gold Prepared via Solid-Phase Reaction. ACS Appl. Energy Mater. 2020, $3,336-343$.

(42) Castillo, E.; Xie, Y.; Dimitrov, N. Filling in Nanoporous Gold with Silver via Bulk Deposition and Surface-Limited Redox Replacement Approaches. Electrochim. Acta 2021, 380, No. 138196.

(43) Chen, L. Y.; Lang, X. Y.; Fujita, T.; Chen, M. W. Nanoporous Gold for Enzyme-Free Electrochemical Glucose Sensors. Scr. Mater. 2011, 65, 17-20.

(44) Zhao, X.; Deng, Z.; Zhao, W.; Feng, B.; Wang, M.; Huang, M.; Liu, L.; Zou, G.; Shao, Y.; Zhu, H. Nanoporous Silver Using Pulsed Laser Deposition for High-Performance Oxygen Reduction Reaction and Hydrogen Peroxide Sensing. Nanoscale 2020, 12, 19413-19419.

(45) Jana, N. R.; Gearheart, L.; Murphy, C. J. Seed-Mediated Growth Approach for Shape-Controlled Synthesis of Spheroidal and Rod-like Gold Nanoparticles Using a Surfactant Template. Adv. Mater. 2001, 13, 1389-1393.

(46) Jana, N. R.; Gearheart, L.; Murphy, C. J. Wet Chemical Synthesis of High Aspect Ratio Cylindrical Gold Nanorods. J. Phys. Chem. B 2001, 105, 4065-4067.

(47) Nikoobakht, B.; El-Sayed, M. A. Preparation and Growth Mechanism of Gold Nanorods (NRs) Using Seed-Mediated Growth Method. Chem. Mater. 2003, 15, 1957-1962.

(48) González-Rubio, G.; Kumar, V.; Llombart, P.; Díaz-Núñez, P.; Bladt, E.; Altantzis, T.; Bals, S.; Peña-Rodríguez, O.; Noya, E. G.; MacDowell, L. G.; Guerrero-Martínez, A.; Liz-Marzán, L. M. Disconnecting Symmetry Breaking from Seeded Growth for the Reproducible Synthesis of High Quality Gold Nanorods. ACS Nano 2019, 13, 4424-4435.

(49) Sánchez-Iglesias, A.; Zhuo, X.; Albrecht, W.; Bals, S.; LizMarzán, L. M. Tuning Size and Seed Position in Small Silver Nanorods. ACS Mater. Lett. 2020, 1246-1250.

(50) Zhuo, X.; Henriksen-Lacey, M.; Jimenez de Aberasturi, D.; Sánchez-Iglesias, A.; Liz-Marzán, L. M. Shielded Silver Nanorods for Bioapplications. Chem. Mater. 2020, 32, 5879-5889.

(51) Li, X.; Lyu, J.; Goldmann, C.; Kociak, M.; Constantin, D.; Hamon, C. Plasmonic Oligomers with Tunable Conductive Nanojunctions. J. Phys. Chem. Lett. 2019, 10, 7093-7099.

(52) Reiser, B.; González-García, L.; Kanelidis, I.; Maurer, J. H. M.; Kraus, T. Gold Nanorods with Conjugated Polymer Ligands: Sintering-Free Conductive Inks for Printed Electronics. Chem. Sci. 2016, 7, 4190-4196.

(53) Zhang, P.; Reiser, B.; González-García, L.; Beck, S.; Drzic, J.; Kraus, T. Drying of Electrically Conductive Hybrid Polymer-Gold Nanorods Studied with in Situ Microbeam GISAXS. Nanoscale 2019, $11,6538-6543$.

(54) Aldous, L.; Silvester, D. S.; Villagrán, C.; Pitner, W. R.; Compton, R. G.; Cristina Lagunas, M.; Hardacre, C. Electrochemical Studies of Gold and Chloride in Ionic Liquids. New J. Chem. 2006, 30, $1576-1583$

(55) Toh, H. S.; Batchelor-McAuley, C.; Tschulik, K.; Compton, R. G. Electrochemical Detection of Chloride Levels in Sweat Using Silver Nanoparticles: A Basis for the Preliminary Screening for Cystic Fibrosis. Analyst 2013, 138, 4292.

(56) Skompska, M.; Vorotyntsev, M. A.; Rajchowska, A.; Levin, O. V. Mixed Solutions of Silver Cation and Chloride Anion in Acetonitrile: Voltammetric and EQCM Study. Phys. Chem. Chem. Phys. 2010, 12, 10525-10535.
(57) García-Morales, N. G.; García-Cerda, L. A.; Puente-Urbina, B. A.; Blanco-Jerez, L. M.; Antaño-López, R.; Castañeda-Zaldivar, F. Electrochemical Glucose Oxidation Using Glassy Carbon Electrodes Modified with $\mathrm{Au}-\mathrm{Ag}$ Nanoparticles: Influence of $\mathrm{Ag}$ Content. J. Nanomaterials 2015, 2015, 1-12.

(58) Cremers, C.; Bayer, D.; Kintzel, B.; Joos, M.; Jung, F.; Krausa, M.; Tübke, J. Oxidation of Alcohols in Acidic and Alkaline Environments. ECS Trans. 2019, 16, 1263-1273.

(59) Monyoncho, E. A.; Woo, T. K.; Baranova, E. A. Ethanol Electrooxidation Reaction in Alkaline Media for Direct Ethanol Fuel Cells. In Electrochemistry; Banks, C.; McIntosh, S., Eds.; Royal Society of Chemistry: Cambridge, 2018; Vol. 15, pp 1-57.

(60) Fan, G.; Sun, P.; Zhao, J.; Han, D.; Niu, L.; Cui, G. Alleviating Concentration Polarization: A Micro Three-Electrode Interdigitated Glucose Sensor Based on Nanoporous Gold from a Mild Process. RSC Adv. 2019, 9, 10465-10472.

(61) Zhao, Y.; Li, X.; Schechter, J. M.; Yang, Y. Revisiting the Oxidation Peak in the Cathodic Scan of the Cyclic Voltammogram of Alcohol Oxidation on Noble Metal Electrodes. RSC Adv. 2016, 6, 5384-5390.

(62) Shen, N.; Xu, H.; Zhao, W.; Zhao, Y.; Zhang, X. Highly Responsive and Ultrasensitive Non-Enzymatic Electrochemical Glucose Sensor Based on Au Foam. Sensors 2019, 19, 1203.

(63) Zhong, S.-L.; Zhuang, J.; Yang, D.-P.; Tang, D. Eggshell Membrane-Templated Synthesis of 3D Hierarchical Porous $\mathrm{Au}$ Networks for Electrochemical Nonenzymatic Glucose Sensor. Biosens. Bioelectron. 2017, 96, 26-32.

(64) Lee, D.; Kim, B.; Kim, J.; Jeong, S.; Cao, G.; Moon, J. Salamilike Electrospun Si Nanoparticle-ITO Composite Nanofibers with Internal Conductive Pathways for Use as Anodes for Li-Ion Batteries. ACS Appl. Mater. Interfaces 2015, 7, 27234-27241.

(65) Ballarin, B.; Cassani, M. C.; Scavetta, E.; Tonelli, D. SelfAssembled Gold Nanoparticles Modified ITO Electrodes: The Monolayer Binder Molecule Effect. Electrochim. Acta 2008, 53, 8034-8044. 